\title{
Trailing in research work
}

\section{Philip Gummett}

Knowing Everything About Nothing: Specialization and Change in Scientific Careers. By John Ziman. Cambridge University Press:1987. Pp.196. £15, \$29.95.

THESE are turbulent times for science in many countries. Rising costs and greater governmental concern about industrial competitiveness are leading to more pressure for exploitability, selectivity and concentration, all within a context of topdown management.

Nowhere is this more true than in Britain, where one effect of this more purposive approach to the management of science is that lines of research are more likely to be stopped than in the past. Partly for this reason. and partly because of the increasing tendency towards short-term funding of posts (compounded, we are told to expect. by the abolition of tenure in British universities), people who wish to make their career in science must increasingly expect from time to time either to be pressed to change their field of research. or actively seek change themselves in order to stay in fields that are likely to gain support.

But, as John Ziman reminds us, whereas it is said of philosophers that they learn less and less about more and more. until they know nothing about everything. of scientists it is said that they learn more and more about less and less, until they know everything about nothing. In science. specialization is the norm. Yet having spent years acquiring the knowledge and craft skills of a particular specialism, how possible is it for a scientist, at the drop of a governmental axe, to switch to a new specialism?

It is this question, posed against the backdrop of the effects of British government policy in recent years, that Ziman examines. Although the book is based on
British experience, the issues raised are of much wider interest.

The specific stimulus to the book was a meeting with the former Secretary of the Natural Environment Research Council (NERC), Mr (now Professor) R.J.H. Beverton. NERC had had radically to reorganize and re-orientate some of its research establishments, and found that a number of scientists had strongly resisted attempts to move them to different research areas, even when they seemed well qualified to take up the new field.

Ziman and Beverton decided to explore in detail the sources of resistance of this kind. Was it caused by the work that the scientisis were doing, or by some aspect of their professional careers, or by the way that they were employed? Was there a stage in their careers when they became so unadaptable that it was scarcely worth the managerial effort to redeploy them on new problems? It soon became clear that, although a conventional wisdom could be said to exist on these questions, very little serious research had been done on them. Sociologists of science have studied research specialities, but not scientists as specialists. The literature is unhelpfully silent on what is now a pressing question in science policy and the management of research and development.

What Ziman and Beverton therefore did, after preliminary discussions with some heads of research councils, departmental chief scientists, directors of research laboratories, and similar people in several countries, was to engage in discussions with groups of staff at 15 research establishments. Seven of these were run by research councils, five were in the public sector, two were in private industry and one was in an academic institution. The book is largely based upon these discussions. Indeed, it has more the flavour of a set of well-honed research notes than of an orthodox monograph. This is not to say that the book is difficult to follow: on the contrary, it has all the lucidity that is normally associated with Ziman's work. The point, rather, is that instead of packaging what the scientists had to say in the language of sociology or management of research and development, Ziman tries to let his readers in on the conversations themselves. We are invited to listen to what the scientists actually had to say, by means of lengthy quotations from the meetings.

The resulting news is both good and bad. Ziman shows how scientists typically spend their careers following what he calls research trails, which are the accumulation of problems with which a scientist engages during his or her career. Most scientists' research trails remain for long periods within one speciality, changing only gradually in terms either of topic or of techniques used. Substantial change is not normally sought.

Nevertheless, a noticeable proportion of scientists follow diverse careers, moving between a wide variety of specialities. Moreover, most scientists are required to learn new skills throughout their career, either because the emphasis of their field shifts, or because of changes in instrumentation, such as have most notably been occasioned by the rise of microcomputers. Typically, scientists in any case use in their work a variety of skills, many of which are drawn from other fields and therefore could be said to equip them for movement. Scientists are also well used to teaching themselves what they need to know about related fields.

What distinguishes the scientist who freely changes fields from the one who sticks to his or her last? No single answer is
Gone fishing - the bloody frogfish Antennarius sanguineus Gill, so-called because of its characteristic reddish-brown to dark-brown spots. The frogfishes (family Antennariidae, one of 18 families of anglerfishes) are distinguished by their unusual frog-like appearance and tetrapod-like locomotion. Brilliantly coloured but cunningly camouflaged to resemble sponge-or coral-encrusted rocks, they attract their prey by wiggling a highly conspicuous lure, a uniquely modified dorsal fin. Frogfishes are the fastest known predators, taking just 6 milliseconds to gulp down their prey. The illustration is taken from Frogfishes of the World: Systematics, Zoogeography, and Behavioral Ecology by Theodore W. Pietsch and David B. Grobecker, just published by Stanford University Press. Price of the book is $\$ 67.50$.

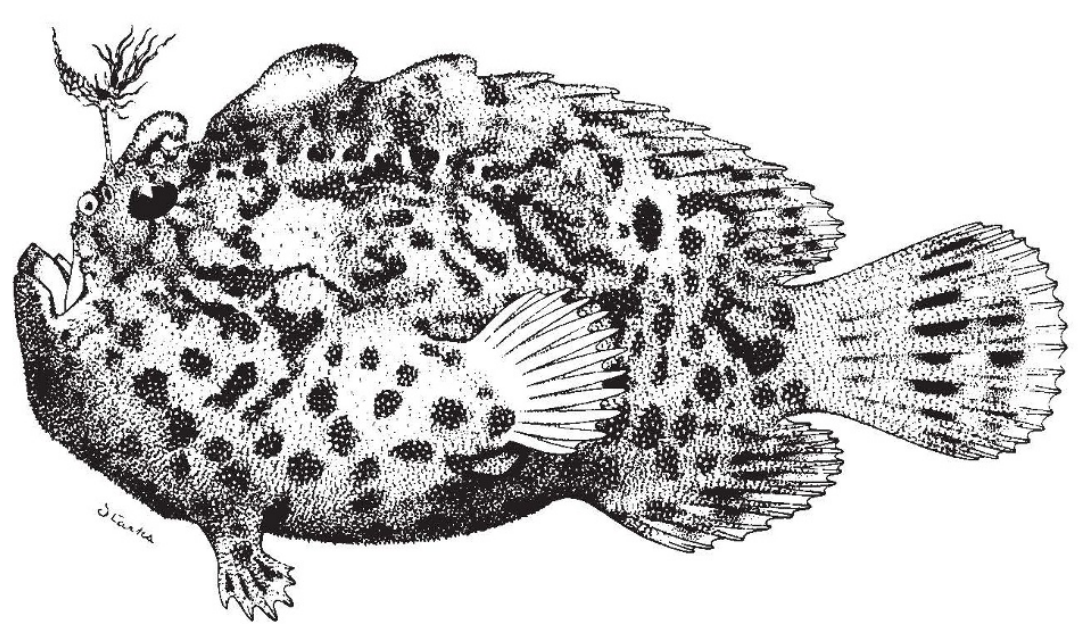

